\title{
СИНТЕЗ УГЛЕРОДНЫХ НАНОТРУБОК С ПОМОЩЬЮ СВЧ: ТЕХНОЛОГИЯ, СВОЙСТВА И СТРУКТУРА
}

\author{
А.В. Щегольков, А.В. Щегольков
}

Тамбовский государственный технический университет (ФГБОУ ВО ТГТУ), ул. Советская, д. 106, Тамбов, Российская Федерация, 392000

E-mail: energynano@yandex.ru, alexxx5000@mail.ru

В статье представлен синтез углеродных нанотрубок (УНТ) с помощью СВЧ, обоснована технология и проведено исследование свойства и структуры УНТ. Приведено описание аппаратурно-технологической схемы синтеза и обоснованы режсмы СВЧ воздействия на каталитические системы на основе ферроценов $\left(\mathrm{C}_{10} \mathrm{H}_{10} \mathrm{Fe}\right)$. Для получения и анализа информации о морфологических особенностях синтезированных УНТ - использован метод сканирующей электронной микроскопии, а такэе спектроскопия комбинационного рассеяния и методы дифференциальной сканирующей калориметрии. УНТ имею ваэнное значение при модифицировании кремнийорганических.матриц в этом отночении в статье имеются исследования, связанные с модифицированием полимеров с помощью синтезированных УНТ. Проводится оценка равномерности распределения УНТ в матрице полимера и исследуется теплопроводность кремнийорганического компаунда при различных концентрациях УНТ. Изменения теплопроводности составляет от 0,2 до $0,32 \mathrm{Bm} / \mathrm{M}^{\circ} \mathrm{C}$ при изменении концентрации УНТ от 1 до $7 \%$.

Ключевые слова: углеродные нанотрубки, синтез, микроволновое излучение, кремнийорганический компаунд

\section{SYNTHESIS OF CARBON NANOTUBES USING MICROWAVE: TECHNOLOGY, PROPERTIES AND STRUCTURE}

\begin{abstract}
A.V. Shchegolkov, A.V. Shchegolkov
Tambov State Technical University (TSTU), Sovetskaya St, 106, Tambov, Russian Federation, 392000

E-mail: energynano@yandex.ru, alexxx5000@mail.ru

The article presents the synthesis of carbon nanotubes (CNTs) using microwave, substantiates the technology and studies the properties and structure of CNTs. The description of the instrumental-technological scheme of synthesis is given and the modes of microwave action on catalytic systems based on ferrocenes $\left(\mathrm{C}_{10} \mathrm{H}_{10} \mathrm{Fe}\right)$ are substantiated. To obtain and analyze information on the morphological features of synthesized CNTs, the method of scanning electron microscopy, as well as Raman spectroscopy and methods of differential scanning calorimetry were used. CNTs are of great importance in the modification of organosilicon matrices in this regard, the article contains studies related to the modification of polymers using synthesized CNTs. The uniformity of distribution of CNTs in the polymer matrix is estimated and the thermal conductivity of the organosilicon compound is investigated at various concentrations of CNTs. The change in thermal conductivity is from 0.2 to $0.32 \mathrm{~W} / \mathrm{m}^{\circ} \mathrm{C}$ with a change in the concentration of CNTs from 1 to $7 \%$.
\end{abstract}

Key words: carbon nanotubes, synthesis, microwave radiation, organosilicon compound

Для цитирования:

Щегольков А.В., Щегольков А.В. Синтез углеродных нанотрубок с помощью СВЧ: технология, свойства и структура. Рос. хим. ж. (Ж. Рос. хим. об-ва). 2021. Т. LXV. № 4. С. 56-60 
For citation:

Shchegolkov A.V., Shchegolkov A.V. Synthesis of carbon nanotubes using microwave: technology, properties and structure. Ros. Khim. Zh. 2021. V. 65. N 4. P. 56-60

Углеродные нанотрубки (УНТ), как однослойные, так и многослойные играют важное значение в создание различных типов электро и теплопроводящих композитных материалов. При этом на свойства композитных материалов модифицированных УНТ существенное влияние оказывает морфология УНТ. Морфология УНТ связана с особенностям синтеза УНТ. В свою очередь существуют различные технологии синтеза УНТ.

Синтез УНТ осуществим с помощью разнообразных методов и технологий [1]. Наибольшее распространение получили следующие методы: метод электро-дугового синтеза (в жидкой и газообразной среде), лазерная абляция, CVD-метод с применением таких газов, как пропан, метан, бутан или других углеродосодержащих газов или их смесей. Однако существуют и другие методы синтеза УНТ, например, метод [2], основанный на механическом воздействии на углеродосодержащие материалы с последующей термической обработкой и дальнейшей механоактивацией, в результате которой происходит формирование и обработка УНТ.

На синтез УНТ влияют различные факторы, такие как давление, температура и объем реакционной зоны, где протекает синтез. В этом отношении имеет быть место технология синтеза с применением в качестве реактора - дизельного ДВС с воспламенением от сжатия. На определенных режимах работы ДВС от сжатия в отработавших газах образуются твердые частицы, которые имеют морфологическую структуру, схожую с УНТ $[3,4]$.

Также существует метод синтеза УНТ с применением СВЧ излучения. СВЧ-воздействие обеспечивает быстрый нагрев по всей глубине углеродосодержащего материала. В качестве углеродосодержащего материала может быть использован ферроцен $\left(\mathrm{C}_{10} \mathrm{H}_{10} \mathrm{Fe}\right)$.

В работе [5] УНТ были быстро синтезированы в течение 20 - 40 с при помощи одностадийного метода микроволнового нагрева.

Медная, молибденовая и железная проволока, а также стальное волокно смешивались с $\mathrm{C}_{10} \mathrm{H}_{10} \mathrm{Fe}$ для достижения быстрого роста УНТ при комнатной температуре на воздухе с помощью бытовой микроволновой печи. Медная, молибденовая и железная проволока, а также стальное волокно применялись для инициирования пиролиза $\mathrm{C}_{10} \mathrm{H}_{10} \mathrm{Fe} \mathrm{c}$ целью стимулирования роста УНТ [6].
УНТ оказывают влияние на электропроводность композитных материалов и обеспечивают реализацию эффекта саморегулированного тепловыделения под действием электрического поля [7-9].

Наиболее быстрым метом синтеза УНТ является синтез с применением СВЧ излучения. Не смотря на преимущества этого метода связанные с быстротой синтеза - для этого метода отсутствует аппратурно-технологическое оформление и нет промышленного оборудования.

Таким образом, основной целью исследований является синтез УНТ и исследование теплофизических свойств наноструктурированных эластомеров, а также разработка аппаратурно-технологической схемы синтеза УНТ при СВЧ воздействие.

В рамках цели исследований были поставлены следующие задачи:

Синтез УНТ с применением ферроцена и графита при СВЧ воздействие.

Исследование свойств синтезированных УНТ, а также зависимости теплопроводности от концентрации УНТ в кремнийорганическом эластомере. Разработка аппаратурно-технологической схемы синтеза УНТ при СВЧ воздействие.

\section{МАТЕРИАЛЫ И МЕТОДЫ}

В качестве катализатора для синтеза УНТ использовали ферроцен $\left(\mathrm{C}_{10} \mathrm{H}_{10} \mathrm{Fe}\right)$ в смеси с графитом в соотношении 5:1. Для синтеза использовали микроволновую печь Samsung ME83KRW-2 (Корея) с мощностью 800 Вт и временем воздействия $20 \mathrm{c}$.

Компонент (А) - кремнийорганический компаунд (силикон) и УНТ смешивали на верхнеприводной механической мешалке WiseStir HT 120DX (Корея) при 200 об/мин в течение 5 мин.

Далее в смесь вводили второй компонент, обеспечивающий полимеризацию (В), с последующим перемешиванием в течение 2 мин. при темпеpaтуре $22{ }^{\circ} \mathrm{C}$. Затем, полученные образцы помещали в вакуумный шкаф и после этого формовали в виде плоских пластин по технологии представленной в работе [9].

Спектры комбинационного рассеяния (КР) УНТ синтезированных УНТ регистрировались на рамановском микроскопе DXR (Raman Microscope Termo Scientific). Длина волны возбуждающего лазера составляла 532 нм.

Термогравиметрический анализ (ТГА) проведен совместно с дифференциальной сканирующей калориметрией (ДСК) (STA 449 F3 Jupiter Netzsch). 
В основе полимерной матрицы был использован эластомер «Силагерм 8030» (ООО "ЭЛЕМЕНТ $14 "$, Москва, Россия) - кремнийорганический компаунд с полярными $\mathrm{Si}-\mathrm{O}$ связями.

СЭМ исследования проводились с использованием электронного микроскопа Hitachi H-800 c ускоряющим напряжением до 200 кэВ.

Для исследования концентрационной зависимости теплопроводности модифицированного УНТ кремнийорганического компаунда использовался прибор для измерения теплопроводности ИИС НК ТФСМ (Россия, Тамбов)

\section{РЕЗУЛЬТАТЫ И ИХ ОБСУЖДЕНИЕ}

СЭМ - изображение МУНТ, синтезированных на катализаторе $\mathrm{C}_{10} \mathrm{H}_{10} \mathrm{Fe}$ с помощью $\mathrm{CBЧ}$ излучения, представлено на рис. 1. На рис. 1 наблюдаются нитевидные образования, обладающие волнистостью, длиной около 1 мкм и более, которые объединены в хаотичные пучки.

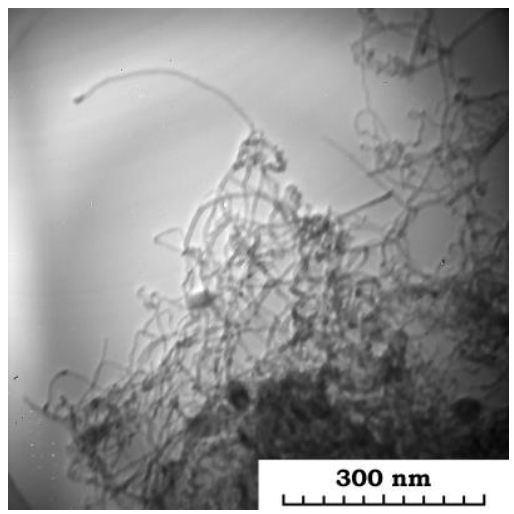

Рис. 1. СЭМ- изображения УНТ (УНT (C $\mathrm{C}_{10} \mathrm{H}_{10} \mathrm{Fe}$ - катализатор)

На рис. 2 представлен рамановский спектр УНТ, синтезированных на $\mathrm{C}_{10} \mathrm{H}_{10} \mathrm{Fe}$ катализаторе c графитом.
Согласно рис. 2 , степень дефектности графеновых слоев УНТ (D/G), синтезированных на $\mathrm{C}_{10} \mathrm{H}_{10} \mathrm{Fe}$ катализаторе, составляет 1,08 .

На рис. 3 представлены ТГ и ДСК синтезированных УНТ.

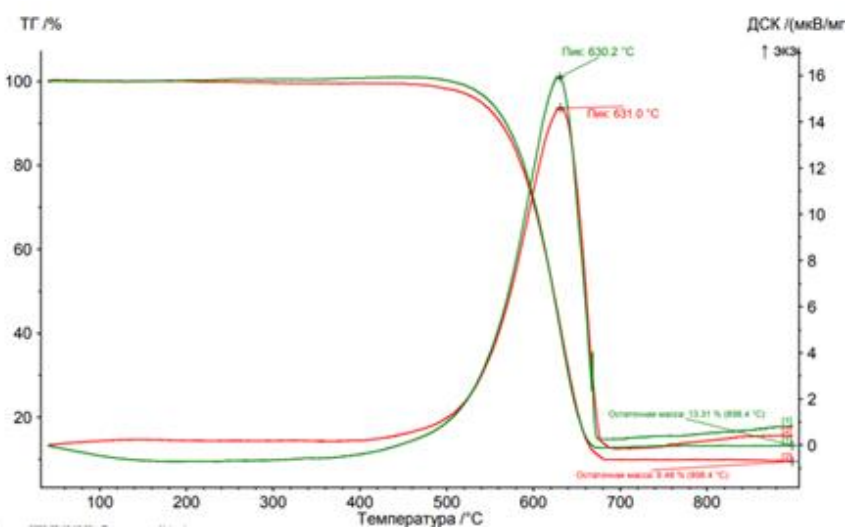

Рис. 3. ТГ и ДСК синтезированных УНТ

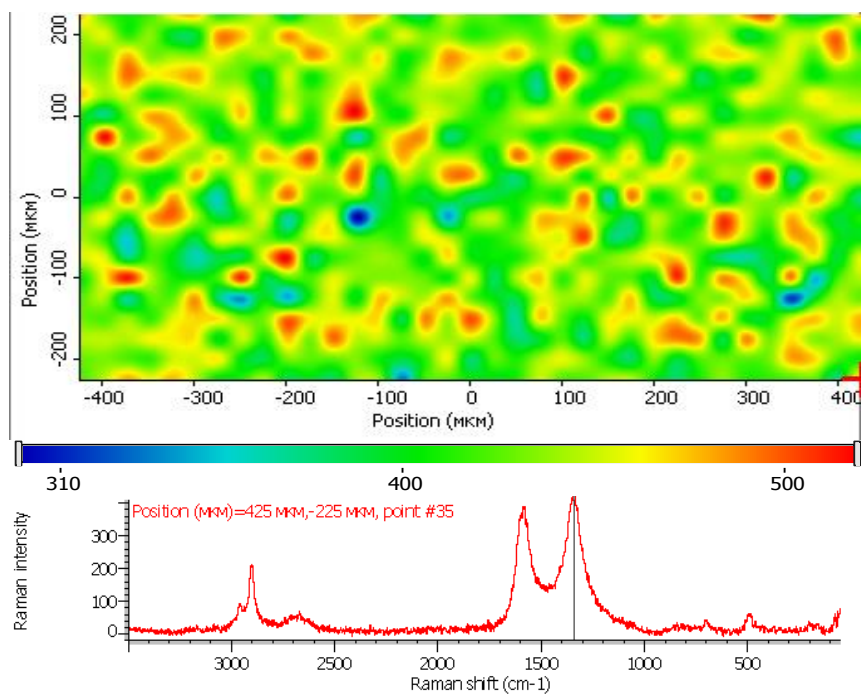

Рис. 4. Рамановское картирование поверхности кремнийорганического компаунда с УНТ

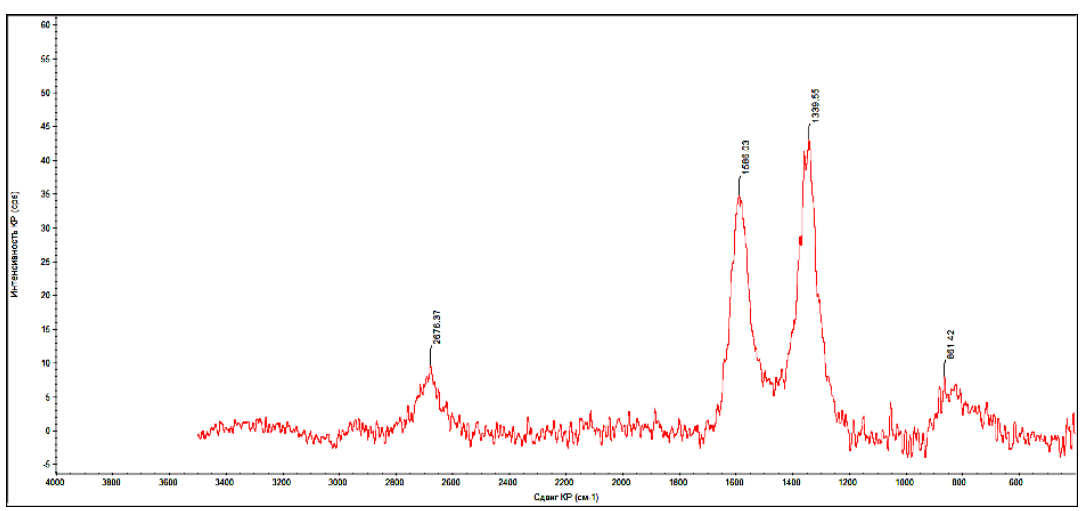

Рис. 2. Рамановский спектр УНТ, синтезированных на $\mathrm{C}_{10} \mathrm{H}_{10} \mathrm{Fe}$ катализаторе
Пиковое значение температуры фазового перехода в УНТ соответствует температуре $630,2{ }^{\circ} \mathrm{C}$ для первого замера и $631{ }^{\circ} \mathrm{C}$ для второго замера.

На рис. 4 представлено рамановское картирование поверхности кремнийорганического компаунда с УHT.

Характер распределения УНТ в структуре эластомера имеет вид микрозамерного локального агломерирования, что характерно для наноразмерных углеродных структур с Ван-дер-Ваальсовым типом взаимодействия $[7,8]$. 
На рис. 5 представлена зависимость теплопроводности кремнийорганического компаунда (наноструктурированного эластомера) от концентрации УНТ.

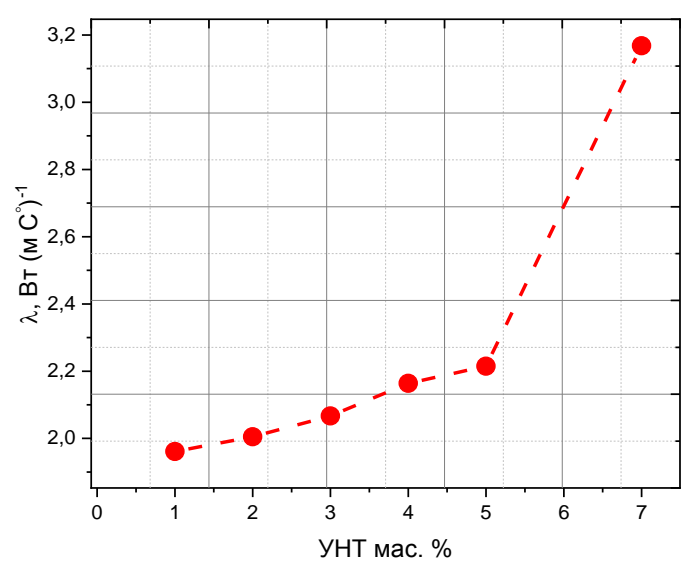

Рис. 5. Зависимость теплопроводности наноструктурированного эластомера от концентрации УНТ

Увеличение массовой концентрации УНТ с 1 до 7\% приводит к повышению теплопроводности кремнийорганического композита. По зависимости теплопроводности от концентрации УНТ прослеживается возрастающий характер изменения теплопроводности от 0,2 до $0,32 \mathrm{BT} / \mathrm{M}^{\circ} \mathrm{C}$.

На рис.6 представлена аппаратурно-технологическая схема синтеза УНТ.

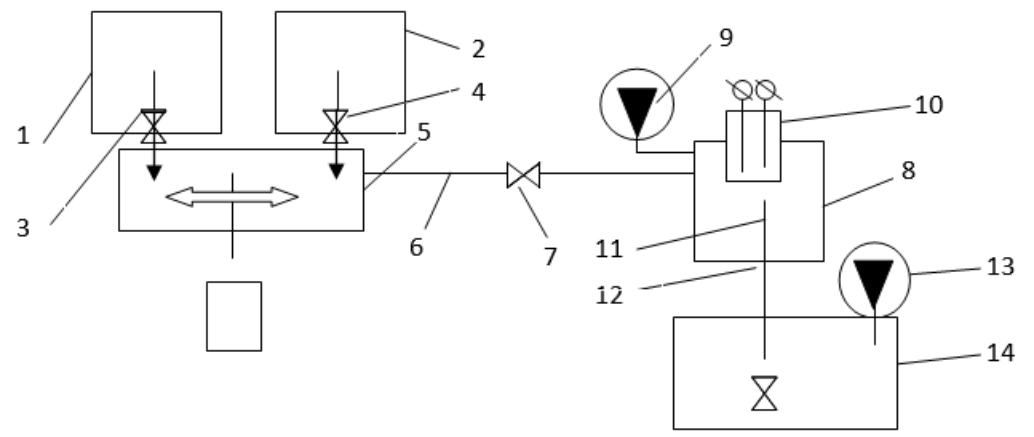

Рис. 6. Аппаратурно-технологическая схема синтеза УНТ

Аппаратурно-технологическая схема синтеза УНТ при СВЧ воздействие на катализатор $\left(\mathrm{C}_{10} \mathrm{H}_{10} \mathrm{Fe}\right)$ (рис. 6) включает в себя две емкости с катализатором 1 и графитом 2 , которые снабжены дозаторами 3 и 4. Ферроцен и графит загружаются в лопастной смеситель 5 в котором реализуется режим перемешивания с псевдоожиным слоем. После смешения вакуумный насос 9 перемещает сыпучий материал по трубопроводу 6 в емкость 8 c
СВЧ излучателем 10, где под действием СВЧ излучения происходит процесс синтеза УНТ. Далее полученный материал вакуумным насосом 13 по трубопроводу 11 при открытом вентиле 12 перемещается в накопительную емкость 14.

Экспериментальные исследования показали, что наиболее эффективным является режим СВЧ воздействия на каталитические системы на основе ферроценов при мощности 800 Вт и временем воздействия 20 с при котором наблюдается формирование углеродных наноструктур.

\section{ЗАКЛЮЧЕНИЕ}

Проведен синтез УНТ с помощью СВЧ воздействия на ферроцен и графит. Для получения информации о морфологических особенностях синтезированных УНТ - использован метод просвечивающейся электронной микроскопии, а также спектроскопия комбинационного рассеяния и методы дифференциальной сканирующей калориметрии. Характер распределения УНТ в структуре эластомера имеет вид микрозамерного локального агломерирования, что характерно для наноразмерных углеродных структур с Ван-дер-Ваальсовым взаимодействием. По зависимости теплопроводности от концентрации УНТ прослеживается возрастающий характер изменения теплопроводности от 0,2 до $0,32 \mathrm{BT} / \mathrm{M}^{\circ} \mathrm{C}$ при изменении концентрации УНТ от 1 до $7 \%$.

Аппаратурно-технологическая схема синтеза включает в себя элементы накопления, дозирования, а также пневмотранспорта - реализованные с помощью вакуумных насосов. Обоснован режим СВЧ воздействия на каталитические системы на основе ферроценов и графита при мощности СВЧ излучения равной 800 Вт и временем воздействия $20 \mathrm{c}$.

\section{ЛИТЕРА Т У Р А REFERENCES}

1. Раков Э.Г. Методы получения углеродных нанотрубок. Успехи химии. 2000. Т. 69 (1). C. 41-59. Rakov E.G. Methods for preparation of carbon nanotubes. Russian Chemical Reviews. 2000. V. 69. N 1. P. 35-52. DOI: 10.1070/RC2000v069n01ABEH000531.

2. Рева В.П., Филатенков А.Э., Мансуров Ю.Н., Курявый В.Г. Этапы формирования многослойных углеродных нанотрубок при механоактивации аморфного углерода. Новые огнеупоры. 2016. № 3. C. 129-133. DOI: 10.17073/1683-4518-2016-3- 
129-133. Reva V.P., Filatenkov A.E., Mansurov Y.N., Kuryavyi V.G. The stages of multilayer carbon nanotubes formation in the course of amorphous carbon mechanical activation. Novye ogneupory (New Refractories). 2016. V. 3. P. 129-133. DOI: 10.17073/1683-4518-2016-3-129-133.

3. Suzuki S., Mori S. Synthesis of carbon nanotubes from biofuel as a carbon source through a diesel engine. Diamond and Related Materials. 2018. P. 79-86. DOI: 10.1016/j.diamond.2018.01.003.

4. Mimi Z., Ganghua P., Yaping W., Tong K., Feifei Zh. Ultrafast carbon nanotube growth by microwave irradiation, Diamond and Related Materials. 2017. P. 65-71. ISSN 0925-9635. DOI: 10.1016/j.diamond.2017.06.001.X.

5. Ohta K., Nishizawa T., Nishiguchi T., Shimizu R., Hattori Y., Inoue S., Katayma M., Mizu-Uchi K., Kono T. Synthesis of carbon nanotubes by microwave heating: Influence of diameter of catalytic Ni nanoparticles on diameter of CNTs. J. Mater. Chem. A. 2014. 2 . P. 2773-2780. DOI: 10.1039/C3TA13297H.

6. Khalilov U., Bogaerts A. \& Neyts E. Atomic scale simulation of carbon nanotube nucleation from hydrocarbon precursors. Nat Commun. 2015. 6. 10306. DOI: 10.1038/ncomms 10306.

7. Щегольков А.В. Вектор науки Тольяттинского государственного университета. 2021. № 1(55). С. 63-73. DOI:
10.18323/2073-5073-2021-1-63-73. Shchegolkov A.V. The comparative analysis of thermal effects in elastomers modified with MCNT at constant dc voltage. Vektor nauki Tolyattinskogo gosudarstvennogo universiteta. 2021. N 1. P. 63-73. DOI: 10.18323/2073-5073-2021-1-63-73.

8. Щегольков А.В. Вестник Магнитогорского государственного технического университета им. Г.И. Носова. 2021. Т. 19. № 2. C. 58-67. DOI: 10.18503/1995-2732-2021-19-2-58-67. Shchegolkov A.V. Multistage Mechanical Activation of MWCNTS to Improve Percolation Transitions in the Elastomer / MWCNTS System: Approaches to the Implementation and Practice of Modifying Elastomers. Vestnik Magnitogorskogo Gosudarstvennogo Tekhnicheskogo Universiteta im. G.I. Nosova [Vestnik of Nosov Magnitogorsk State Technical University]. 2021. V. 19. N 2. P. 58-67. DOI: 10.18503/19952732-2021-19-2-58-67.

9. Ali I., AlGarni T.S., Shchegolkov A., Shchegolkov A., Jang S.H., Galunin E., Komarov F., Borovskikh P., Imanova G.T. Polymer Bulletin. 2021. Article in press. DOI: 10.1007/s00289-02003483-y.

Поступила в редакциию (Received) 01.08.2021 Принята к опубликованию (Accepted) 03.09.2021 